Foro, Nueva época, vol. 21, núm. 2 (2018): 19-44

http://dx.doi.org/10.5209/FORO.64016

\title{
CONOCIMIENTO POR LOS PARLAMENTARIOS DE LAS MATERIAS CLASIFICADAS EN VIRTUD DE LA LEY DE SECRETOS OFICIALES
}

\author{
Ángel Luis Alonso De ANTONIO \\ Departamento de Derecho Constitucional \\ Facultad de Derecho \\ Universidad Complutense de Madrid \\ anlualan@der.ucm.es
}

\begin{abstract}
RESUMEN
El control parlamentario sobre los secretos oficiales en España se regula a través de una resolución de la Presidencia del Congreso de los Diputados que establece un mecanismo plural según que la materia haya sido declarada secreta o reservada. Dicho control se lleva a cabo por un reducido número de diputados que no pueden conservar la documentación a la que tienen acceso y que deben guardar además secreto de lo que conozcan sobre esas materias.
\end{abstract}

Palabras clave: secretos oficiales, control parlamentario, materias clasificadas, diputados, deber de secreto.

\section{ABSTRACT}

The monitoring of MPs on official secrets in Spain is ruled through a Resolution by the Presiding Officer of the House of Commons who settles a plural procedure depending on whether the subject of discussion is considered secret or of a reserved nature. Such control is carried by a limited number of MPs who cannot retain the files they have access to and who must also keep their knowledge on such matters secret.

Keywords: Official secrets, monitoring of MPs, classified matters, MPs, secret compliance.

\section{ZUSSAMENFASSUNG}

Die parlamentarische Kontrolle über die Staatsgeheimnisse wird in Spanien durch eine Entschließung des Präsidialamts des Abgeordnetenkongresses geregelt, welche einen pluralen Mechanismus festlegt, nach welchem die Dokumente als »streng vertraulich" oder »vertraulich" eingestuft werden. Diese Kontrolle wird durch eine begrenzte Anzahl von Abgeordneten ausgeübt, welche die Dokumente, zu denen sie Zugang haben, nicht aufbewabren dürfen und bezüglich ibrer diesbezüglichen Kenntnisse zur Verschwiegenheit verpflichtet sind.

Schlüsselwörter: Staatsgeheimnisse, parlamentarische Kontrolle, vertrauliche Dokumente, Abgeordnete, Verschwiegenheitspflicht. 
Ángel Luis Alonso de Antonio Conocimiento por los parlamentarios de las materias...

SUMARIO: I. INTRODUCCIÓN.-II. FUNDAMENTO JURÍDICO DEL DERECHO DE ACCESO POR LOS PARLAMENTARIOS A LA INFORMACIÓN SOBRE MATERIAS CLASIFICADAS.-III. CARACTERIZACIÓN JURÍDICA DEL INSTRUMENTO QUE REGULA LA COMUNICACIÓN A LOS PARLAMENTARIOS DE LAS MATERIAS CLASIFICADAS.-IV. EVOLUCIÓN HISTÓRICA DE LA REGULACIÓN SOBRE ACCESO DE LOS PARLAMENTARIOS A LAS MATERIAS CLASIFICADAS.-V. LA REGULACIÓN ACTUAL SOBRE ACCESO DE LOS PARLAMENTARIOS A LAS MATERIAS CLASIFICADAS.-VVI. CONCLUSIONES.

\section{INTRODUCCIÓN}

El fallecimiento en acto de servicio en el Líbano, el 28 de enero de 2015, del cabo del Ejército de Tierra español Francisco Javier Soria Toledo volvió a poner de manifiesto un tema que se plantea de forma periódica y sobre el que pueden suscitarse dudas razonables con respecto a la idoneidad de la solución que ha venido dándosele hasta ahora. Se trata del acceso y conocimiento por los parlamentarios de las materias clasificadas en virtud de la Ley 9/1968, de 5 de abril, de Secretos Oficiales (en adelante, LSO). Es una cuestión sensible en general por los efectos que el conocimiento y eventual utilización o revelación de dichas materias puede ocasionar en orden a la seguridad y mantenimiento del Estado, pero, sin duda, la particularidad de la situación se incrementa si tenemos en cuenta que en estas líneas trataremos, en especial, el acceso a dichas informaciones por los miembros del Parlamento, constitucionalmente representantes del pueblo español (art. 66.1).

Se deben conjugar por ello, en difícil equilibrio sin duda, dos ideas perfectamente legítimas y defendibles. Por una parte, la natural reserva que debe rodear a las materias clasificadas en aplicación de la LSO en sus dos categorías de secreto y reservado, porque, de lo contrario, el objetivo que se predica con esa calificación quedaría vulnerado y, por tanto, sin contenido si esas materias pudiesen ser conocidas con carácter general. De otro lado, la publicidad y transparencia que es consustancial al sistema democrático hace que la idea del secreto sea la excepción porque a su amparo pueden cobijarse abusos intolerables incompatibles con el Estado de Derecho que proclama nuestra Constitución.

De lo que precede se desprende que las Cortes Generales no deben ser simples receptoras de explicaciones más o menos elaboradas y leídas de forma mecánica en sede parlamentaria, sino que deben recibir en tiempo y forma, con la mayor diligencia que sea posible, el contenido de cuantos informes, documentos o materiales tengan relación con el asunto con- 
creto que estén estudiando, que haya sido clasificado según la LSO y sobre el que soliciten información al Gobierno. Cuestión distinta será evaluar el modo concreto a través del cual esa información puede o debe suministrarse a los parlamentarios, ya que es de suyo que en ciertos supuestos tal vez no deban ser puestas a su disposición con un carácter general porque su contenido aconseje rodear esas explicaciones de las garantías acordes con el carácter sensible que pueda caracterizar a ese material.

El caso concreto que hemos señalado al principio es bien ilustrativo de lo que se comenta. Producido el fallecimiento del cabo Soria Toledo, el ministro de Defensa compareció a petición propia ante la Comisión de Defensa del Congreso el 14 de abril de 2015 donde señaló que sobre ese luctuoso hecho se habían realizado tres investigaciones, «tanto la que lanzamos unilateralmente con inmediatez como aquella que instamos en Naciones Unidas y también la que hemos hecho conjuntamente con el Gobierno de Israel» ${ }^{1}$. Dichos informes no habían llegado a la Comisión de Defensa, lo que motivó intervenciones críticas de algunos parlamentarios. Así, el diputado Sanz Remón, de La Izquierda Plural, sostuvo que «es lamentable que no tengamos hasta escucharle a usted más información del contenido de esos informes, del de Naciones Unidas y del elaborado por Israel que fue acompañado por el Gobierno español; es lamentable que nosotros no tengamos más información que la que salió en la prensa» ${ }^{2}$; el socialista López Garrido preguntó primeramente al ministro «por qué no nos han enviado los informes a los que usted se ha referido a esta Comisión; quisiera saber si se van a enviar» ${ }^{3}$ o, por último, el diputado del Grupo Parlamentario Catalán Jordi Xuclà i Costa señaló que «la función del Parlamento tiene que ser la de interpelar al Gobierno sobre los hechos, la investigación sobre los mismos y requerir la información necesaria [...] hoy, en sede parlamentaria, es la hora de la verdad, la hora en la cual usted nos tiene que trasladar todo tipo de información a partir de los hechos [...] en este caso, no hoy con una proyección en una pantalla pero en el futuro, creo que usted, señor ministro, debe trasladar a los grupos los informes y las conclusiones del informe del Gobierno de Israel, de Naciones Unidas y del Gobierno español, y exactamente conocer el perímetro del teatro» ${ }^{4}$. La respuesta del ministro Morenés al decir que «lo que les he

\footnotetext{
${ }^{1}$ Cortes Generales, Diario de Sesiones del Congreso de los Diputados, Comisiones, X Legislatura, núm. 784, Defensa, Sesión núm. 39, martes 14 de abril de 2015, p. 2.

${ }^{2}$ Ibid., p. 5.

3 Ibid., p. 8.

${ }^{4}$ Ibid., p. 11.
} 
leído aquí son exactamente las conclusiones [...] de los tres informes y además he dicho que coinciden los tres [...] creo que ustedes han tenido y tienen toda la información para que cada uno llegue a la conclusión de lo que me ha planteado» ${ }^{5}$ no satisfizo a todos, lo que motivó que por los diputados López Garrido y Xuclà i Costa se volviese a insistir en la petición al ministro del envío de los referidos informes ${ }^{6}$.

Especialmente notoria fue la iniciativa posterior del diputado López Garrido, quien formuló el 28 de abril de 2015 una pregunta al Gobierno para que le fuera contestada por escrito, en concreto: «¿Qué actuaciones ha realizado el Gobierno ante el Estado de Israel y la Organización de Naciones Unidas para exigir la depuración de las responsabilidades disciplinarias y, en su caso, penales de los autores de los disparos de artillería que acabaron con la vida del cabo Francisco Javier Soria Toledo el pasado 28 de enero de 2015 ?» ${ }^{7}$. La respuesta escrita del secretario de Estado de Relaciones con las Cortes, de 11 de mayo de 2015, fue escueta, limitándose a señalar que «en relación con la información solicitada se señala que, en caso de hacerse pública, podría comprometer la seguridad de las fuerzas participantes en la operación, por lo que se encuentra sujeta a clasificación de seguridad. Aquella parte de la información relativa exclusivamente a los hechos que produjeron la muerte al cabo Francisco Javier Soria, las conclusiones extraídas y las medidas adoptadas fueron comunicadas por el ministro de Defensa en comparecencia a petición propia, número de expediente 214/125, de 14 de abril de 2015, Diario de Sesiones núm. 784, ante la Comisión de Defensa del Congreso de los Diputados, y su contenido figura en las actas publicadas en el Boletín Oficial de las Cortes Generales» ${ }^{8}$. La verdadera respuesta, aunque fuera «oral», a esa pregunta se produjo en la sesión de la Comisión de Defensa de 27 de mayo de 2015 cuando la diputada Moreno Felipe, del Grupo Popular, apuntó que «tampoco estamos de acuerdo en lo que ustedes dicen de que no se les ha proporcionado los informes porque ustedes conocen perfectamente que esos informes son clasificados, que además dos de ellos no son titularidad del Estado español y, por tanto, al no ser obligación del Estado, son de Naciones Unidas y de las fuerzas israelíes, no

5 Ibid., p. 14.

${ }^{6}$ Ibid., pp. 17 y 18.

7 Boletín Oficial de las Cortes Generales, Congreso de los Diputados, X Legislatura, Serie D, núm. 668, 20 de mayo de 2015, p. 86.

${ }^{8}$ Boletín Oficial de las Cortes Generales, Congreso de los Diputados, X Legislatura, Serie D, núm. 689, 23 de junio de 2015, p. 307. 
pueden ser entregados por el Estado español porque no han sido elaborados por el Estado español. Y, como saben, son informes clasificados con base en la Ley 9/1968, de 5 de abril, de Secretos Oficiales, y el acuerdo del Consejo de Ministros de 15 de octubre de 2010 sobre política de seguridad de la información del Ministerio de Defensa. Por tanto, como decimos, no es verdad que no se hayan dado explicaciones y tampoco es cierto que se pueden distribuir los informes porque, como ustedes saben, los informes clasificados no pueden ser distribuidos en la medida en que lo solicitan» ${ }^{9}$. La decisión de clasificar una materia con arreglo a la LSO no se publica en el Boletín Oficial del Estado ni aparece en la relación de acuerdos adoptados por el Consejo de Ministros, por lo que el secreto es total al ser confidencial el acuerdo por el que algo se declara secreto.

Por tanto, no es conocido que la información relativa al fallecimiento del cabo Soria haya sido o no declarada secreta, aunque bien pudiera haberlo sido en aplicación de la LSO. Ahora bien, lo que no está claro es la referencia a la otra causa de negación de los informes solicitados. En la página web oficial del Ministerio de Defensa se cita como normativa aplicable al efecto la Orden Ministerial 76/2006, de 19 de mayo, por la que se aprueba la política de seguridad de la información del Ministerio de Defensa (Boletín Oficial de Defensa, núm. 103, de 29 de mayo de 2006) ${ }^{10}$. Tal vez la diputada Moreno Felipe se refiriera al Acuerdo del Consejo de Ministros de 15 de octubre de 2010 titulado «Acuerdo sobre política de seguridad de la información del Ministerio de Asuntos Exteriores y de Cooperación por el que se clasifican determinadas materias con arreglo a la Ley de Secretos Oficiales», y que ha podido ser conocido porque lo solicitó el profesor de la Universidad Complutense Carlos Sanz Díaz ante la imposibilidad sobrevenida de consultar determinada documentación del Archivo del Ministerio de Asuntos Exteriores y de Cooperación ${ }^{11}$.

\footnotetext{
${ }^{9}$ Cortes Generales, Diario de Sesiones del Congreso de los Diputados, Comisiones, X Legislatura, núm. 820, Defensa, Sesión núm. 41, miércoles 27 de mayo de 2015, p. 16.

${ }_{10}$ http://www.defensa.gob.es/politica/infraestructura/seguridad-informacion/.

${ }^{11}$ El texto puede verse en http://www.madrimasd.org/blogs/Historia.RRII/2012/05/ 16/130311.
} 


\section{FUNDAMENTO JURÍDICO DEL DERECHO DE ACCESO POR LOS PARLAMENTARIOS A LA INFORMACIÓN SOBRE MATERIAS CLASIFICADAS}

El derecho de acceso por los parlamentarios a la documentación clasificada en virtud de la LSO tiene una doble fundamentación jurídica: constitucional y legal.

En efecto, desde el punto de vista constitucional, y con un carácter genérico en relación con todos los ciudadanos, el art. 105.b) CE señala que la ley regulará «el acceso de los ciudadanos a los archivos y registros administrativos, salvo en lo que afecte a la seguridad y defensa del Estado, la averiguación de los delitos y la intimidad de las personas». Obviamente, dado el carácter específico de la condición de parlamentarios, hay que tener en cuenta en primer lugar el art. 109 CE, según el cual «las Cámaras y sus Comisiones podrán recabar, a través de los presidentes de aquellas, la información y ayuda que precisen del Gobierno y de sus Departamentos y de cualesquiera autoridades del Estado y de las Comunidades Autónomas», y de una forma muy destacada el art. 23 CE, cuyo primer párrafo establece que «los ciudadanos tienen el derecho a participar en los asuntos públicos, directamente o por medio de representantes, libremente elegidos en elecciones periódicas por sufragio universal», mientras que el segundo especifica que «asimismo tienen derecho a acceder en condiciones de igualdad a las funciones y cargos públicos, con los requisitos que señalen las leyes».

De la lectura del último precepto citado y de la interpretación que del mismo realizó en su momento el Tribunal Constitucional puede deducirse que el derecho que se comenta es, en realidad, reflejo del derecho de acceso a esa documentación de los españoles, tamizado a través del filtro del derecho de acceso de los parlamentarios. En efecto, partiendo del hecho de que, según ese art. 23.1, los ciudadanos participan indirectamente en los asuntos públicos a través de sus representantes, cualquier iniciativa de estos últimos en la materia de que se trata significa que por ese conducto los ciudadanos pueden llegar a su conocimiento, como aparece en la STC 161/1987, de 20 de septiembre, cuando al resolver un recurso de amparo presentado por cuatro diputados de las Cortes de Castilla-La Mancha contra el Acuerdo de la Mesa de dichas Cortes de 27 de octubre de 1986, por el que se denegó la admisión a trámite de la documentación pedida al Consejo de Gobierno de la Junta de Comunidades por dichos dipu- 
tados, el Tribunal Constitucional manifiesta que «la norma contenida en el art. 23.1 resulta inseparable de la del 23.2 cuando se trata, como aquí ocurre, de una petición de amparo deducida por representantes parlamentarios en defensa del ejercicio de sus funciones, ya que ello comporta defender también el derecho mismo de los ciudadanos a participar a través de la institución de la representación en los asuntos públicos (SSTC 10/1983, de 21 de febrero, y 32/1985, de 6 de marzo)» (FJ 5. ${ }^{\circ}$.

El segundo aspecto a destacar es la fundamentación legal, en concreto en el caso en presencia de lo que el Tribunal Constitucional denominó en su momento la «legalidad parlamentaria» (STC 33/2010, de 19 de julio, FJ 3. ${ }^{\circ}$ ). En la citada STC 161/1987, de 20 de septiembre, el Tribunal Constitucional establece la base legal de la fundamentación del derecho de los parlamentarios a acceder a la documentación, introduciendo por vez primera el concepto del ius in offcium de los parlamentarios. Señala el Tribunal Constitucional que «el derecho fundamental del art. 23.2 de la Constitución [...] es un derecho de configuración legal, como de forma inequívoca expresa el último inciso del precepto, y, en consecuencia, compete a la Ley, comprensiva, según se deja dicho, de los reglamentos parlamentarios, el ordenar los derechos y facultades que corresponden a los distintos cargos y funciones públicos. Una vez creados por las normas legales tales derechos y facultades, estos quedan integrados en el status propio de cada cargo con la consecuencia de que podrán sus titulares, al amparo del art. 23.2 de la Constitución, defender ante los órganos judiciales $-\mathrm{y}$ en último extremo ante este Tribunal- el ius in officium que consideren ilegítimamente constreñido o ignorado por actos del poder público, incluidos los provenientes del propio órgano en el que se integren los titulares del cargo, con la especialidad de que si el órgano es parlamentario la defensa del derecho deberá promoverse directamente ante esta jurisdicción constitucional en aplicación de lo dispuesto en el art. 42 LOTC» (FJ 7. ${ }^{\circ}$. La conclusión en aquel caso fue que «en razón a todo ello, debemos aquí dejar establecido que, en principio, el art. 12.2 del Reglamento citado (el de las Cortes de Castilla-La Mancha) crea a favor de los parlamentarios castellano-manchegos un derecho individual a recabar, en la forma y con los requisitos que el mismo reglamento establece, información a la Administración regional, el cual, por venir integrado en el status propio del cargo de diputado, se inserta y forma parte del derecho fundamental que garantiza el art. 23.2 de la Constitución» (FJ 7. ${ }^{\circ}$ ).

La señalada doctrina del Tribunal Constitucional resulta extrapolable al conjunto de los parlamentarios, incluidos desde luego los miembros 
de las Cortes Generales. En efecto, el derecho de acceso a la documentación de estos últimos tiene su apoyo legal en los reglamentos parlamentarios. Así, el art. 7.1 del Reglamento del Congreso de los Diputados (en adelante, RCD) establece un derecho individual de cada diputado (STC 203/2001, de 15 de octubre, FJ 3..$^{\circ}$ ) al señalar que «para el mejor cumplimiento de sus funciones parlamentarias, los diputados, previo conocimiento del respectivo grupo parlamentario, tendrán la facultad de recabar de las Administraciones Públicas los datos, informes o documentos que obren en poder de estas»; previsión completada en el párrafo 2 según el cual «la solicitud se dirigirá, en todo caso, por conducto de la Presidencia del Congreso y la Administración requerida deberá facilitar la documentación solicitada o manifestar al presidente del Congreso, en plazo no superior a treinta días y para su más conveniente traslado al solicitante, las razones fundadas en Derecho que lo impidan». Idéntica regulación, adaptada al Senado, se encuentra en el art. 20.2 del Reglamento del Senado (en adelante, RS). Cuestión distinta es el derecho colectivo de las Comisiones, que podrán recabar, por conducto del presidente del Congreso, «la información y la documentación que precisen del Gobierno y de las Administraciones Públicas, siendo aplicable lo establecido en el apartado 2 del art. 7» (art. 44.1 RCD). En el Senado, las Comisiones también pueden recabar, a través del presidente del Senado, «la información y ayuda que necesiten del Gobierno y de sus Departamentos y de cualesquiera autoridades del Estado y de las Comunidades, así como la documentación necesaria cuando lo solicite un tercio de los miembros de la Comisión, siendo aplicable lo establecido en el apartado 2 del art. 20. Asimismo, podrán solicitar la presencia de otras personas para ser informadas sobre cuestiones de su competencia» (art. 67 RS). No hay que olvidar, además, la norma general que en la actualidad desarrolla el mandato del art. 105.b) CE y por ello hay que tener también presente el título I («Transparencia de la actividad pública»), capítulo III («Derecho de acceso a la información pública»), arts. 12-24, de la Ley 19/2013, de 9 de diciembre, de Transparencia, Acceso a la Información Pública y Buen Gobierno.

La importancia de los citados preceptos reglamentarios es notoria y así lo entendió el Tribunal Constitucional vinculándolos con la esencia de la función parlamentaria. En concreto, la mención inicial del art. 7.1 RCD («para el mejor cumplimiento de sus funciones parlamentarias») lo interpretó en el sentido de que «ha de entenderse referido, en concreto, a la función de fiscalizar o controlar la acción del Gobierno [...] constituyendo así un aspecto particular de la función de control genéricamente atri- 
buida a las Cortes Generales en el art. 66.2 CE» (STC 203/2001, de 15 de octubre, FJ $3 .^{\circ}$ ). En todo caso, hay que perfilar con precisión los aspectos nucleares de la función parlamentaria que deben incluirse en el contenido del ejercicio del art. 23.2 CE, y sobre el particular el Tribunal Constitucional es claro al considerar que «solo poseen relevancia constitucional, a estos efectos, los derechos o facultades atribuidos al representante que pertenezcan al núcleo de su función representativa fundamental, como son, indudablemente, el ejercicio de la función legislativa o de control de la acción de Gobierno» (STC 1/2015, de 19 de enero, FJ 3. ${ }^{\circ}$ ). Resulta obvio que la genérica solicitud de documentación —o, lo que aquí interesa específicamente, de documentación clasificada - se incardina en la esencia de la función parlamentaria, pues constituye un instrumento de control al ejecutivo por el interés en conocer alguna de sus decisiones previas cuyo análisis se ve condicionado en sede parlamentaria por su consideración posterior como materia clasificada.

\section{CARACTERIZACIÓN JURÍDICA DEL INSTRUMENTO QUE REGULA LA COMUNICACIÓN \\ A LOS PARLAMENTARIOS DE LAS MATERIAS CLASIFICADAS}

En la actualidad, el instrumento jurídico utilizado para regular el procedimiento por el que los diputados conocen de las materias clasificadas en aplicación de la LSO es una Resolución de la Presidencia de la Cámara de 11 de mayo de 2004, algo por lo demás que viene sucediendo desde la primera regulación de este tema el 18 de diciembre de 1986. En esa primera experiencia ya se originaron problemas de interpretación que dieron lugar incluso a la presentación de un recurso de amparo ante el Tribunal Constitucional por parte de sesenta y siete diputados por considerar que esa Resolución de 1986 vulneraba su derecho fundamental a «comunicar o recibir libremente información veraz por cualquier medio de difusión» (art. 20.1 CE), al tiempo que infringiría el art. 7 del Reglamento del Congreso de los Diputados y el art. 10.2 LSO. El amparo se desestimó por STC 118/1988, de 20 de junio, pero ese pronunciamiento del Tribunal Constitucional fue esencial para determinar con precisión algunas de las características de este tipo de resoluciones.

En primer lugar, y en contra del parecer en aquel recurso de amparo del letrado del Estado e, indirectamente, del Ministerio Fiscal, la resolu- 
ción no cabría incluirla en la categoría de los interna corporis acta, calificación que implica la regulación de extremos que solo afectan a las relaciones entre una Cámara y sus integrantes, y, en consecuencia, supone ausencia de implicaciones respecto a terceros y la exclusión de su conocimiento por parte de los tribunales ordinarios y del propio Tribunal Constitucional. Este concepto aparece en la jurisprudencia del supremo intérprete de la Constitución, pero en ella también se dice que «la doctrina de los interna corporis acta solo es aplicable en la medida en que no exista lesión de tales derechos y libertades, impidiendo el conocimiento de este Tribunal de lo que no sea su posible lesión. "Quiere con ello decirse que, solo en cuanto lesionan un derecho fundamental reconocido en la Constitución y no por infracción pura y simple de un precepto de la Cámara, son recurribles en amparo tales actos, en virtud de lo dispuesto en el art. 42 de la Ley Orgánica del Tribunal Constitucional"(ATC de 11 de marzo de 1987). En cuanto un acto parlamentario afecte a un derecho o libertad susceptible de amparo constitucional, sale o trasciende de la esfera irrevisable propia de los interna corporis acta y corresponde a este Tribunal el examen, pero solo ello, de la virtual lesión de tales derechos o libertades (ATC 12/1986, de 15 de enero)» (STC 118/1988, de 20 de junio, FJ 2. ${ }^{\circ}$ ).

Ciertamente, aquella primera resolución y las dos que le han seguido regulan relaciones no meramente internas en el seno de una Cámara, en este caso el Congreso de los Diputados, sino que también implican a un tercero, el Gobierno, a quien se le reconoce además en esta materia, como veremos, algún grado de discrecionalidad que matiza ese carácter interno que se le quiso atribuir en su momento.

La segunda nota característica de este tipo de resoluciones es que se trata de una norma jurídica y no de un acto o decisión. La STC 118/1988, de 20 de junio, es muy esclarecedora al respecto. En el recurso de amparo de la que trae causa, los recurrentes estimaban que la Resolución de 18 de diciembre de 1986 era simplemente una decisión o acto susceptible de recurrirse en amparo, como así hicieron, en tanto que el letrado de las Cortes Generales y el letrado del Estado entendían que la misma se incardinaba con carácter general y contenido normativo en el ordenamiento parlamentario. Realmente esa era la posición jurídicamente defendible, porque se trataba de regular con vocación de continuidad una materia que adolecía de un inexplicable y aun peligroso silencio en el Reglamento de la Cámara, en este caso el Congreso de los Diputados, no siendo por ello una solución puntual que se agotara en la mera aplicación en un supuesto específico. Nada de eso sucedía entonces ni ha suce- 
dido luego. La materia que se comenta sigue estando regulada por una resolución de este tipo.

En la sentencia de referencia, el Tribunal Constitucional asumía la tesis del contenido normativo de la resolución al entender que «se trata, sin duda, por su contenido, de una disposición de carácter general, que se integra de modo permanente en el ordenamiento parlamentario y que es susceptible de una pluralidad de actos de aplicación singular, por lo que no se agota con su cumplimiento. Por todas estas razones, no se puede negar que la resolución recurrida es una norma jurídica y no un acto siquiera general- de aplicación. Pese a la ocasión concreta para dictarla, en la que pudo detectarse la inexistencia de una regla en el reglamento que regulara el tema, la resolución del presidente del Congreso no ha pretendido dictar una regulación singular o de excepción respecto a un caso único y concreto, sino de introducir, como innovación normativa, una regla general que se aplique en el futuro a todos los casos similares, insertándose por ello en el ordenamiento jurídico parlamentario» (STC 118/1988, de 20 de junio, FJ 3. ${ }^{\circ}$. Se asimilaba, pues, la Resolución de 1986 al Reglamento del Congreso de los Diputados porque entendía el Tribunal Constitucional que la habilitación del art. 32.2 RCD a la Presidencia de la Cámara para que la pudiera dictar lo era «para suplir omisiones o para interpretarlo, no para desarrollarlo o especificar sus prescripciones, por lo que, aun con las debidas distancias, nos encontramos ante un supuesto cercano al de integración normativa o de "delegación recepticia", de modo que la resolución supone el ejercicio de una facultad normativa delegada para suplir o interpretar, sin modificar, regulaciones existentes en el Reglamento de la Cáma$\mathrm{ra}$, pasando a integrarse en la reglamentación parlamentaria de la materia, en este caso de acceso a los secretos oficiales dentro del Congreso de los Diputados, materia típica de los reglamentos parlamentarios, como muestran las experiencias comparadas» (FJ 4. ${ }^{\circ}$ ).

Corolario de lo anterior, en tercer lugar, es que este tipo de resoluciones que regulan el acceso de los parlamentarios a las materias clasificadas, al asimilarse a la categoría de reglamento parlamentario y tener valor de ley en aplicación de la Ley Orgánica del Tribunal Constitucional, no son susceptibles de ser cuestionadas, como era el caso, a través de la figura del recurso de amparo, sino que tienen su cauce natural de revisión a través del recurso de inconstitucionalidad en virtud del art. 27.2.d) de la citada Ley Orgánica, teniendo en cuenta además que el Tribunal Constitucional en la Sentencia 118/1988, de 20 de junio, entendió que debía aducirse «la exigencia institucional de arbitrar y defender un equilibrio constitucional- 
mente aceptable entre la independencia de las Cámaras y la defensa de las minorías. Este equilibrio solo puede conseguirse si se atribuye valor de ley, a efectos de su revisión plena por este Tribunal, a disposiciones normativas como las que ahora se contemplan, en la medida que permite la defensa de las minorías, en cuanto que grupos o colectivos (formales u ocasionales) de diputados, a través del más amplio y extenso, en cuanto a su objeto, recurso de inconstitucionalidad» $\left(\mathrm{FJ} 4 .^{\circ}\right)$.

\section{EVOLUCIÓN HISTÓRICA DE LA REGULACIÓN SOBRE ACCESO DE LOS PARLAMENTARIOS A LAS MATERIAS CLASIFICADAS}

Hasta el momento se han aprobado tres resoluciones por la Presidencia del Congreso de los Diputados sobre la materia. La primera regulación en 1986 no se debió a un propósito deliberado de suplir una clara laguna reglamentaria sin un particular asunto previo que incitara a ello. Bien al contrario, se debió al intento de adoptar una solución genérica con vocación de permanencia para regular el acceso de los diputados a las materias clasificadas en virtud de la LSO, pero partiendo de una realidad específica que se había presentado en relación con la OTAN. En concreto, el Pleno del Congreso de los Diputados aprobó el 15 de octubre de 1986 el siguiente acuerdo: «El Pleno del Congreso de los Diputados, en su sesión del día de hoy, con motivo del debate de la moción consecuencia de interpelación urgente sobre memorándum presentado por el Gobierno en la Secretaría General de la OTAN (núm. de expediente 173/00003) y de las enmiendas formuladas a la misma, ha aprobado lo siguiente: "La Presidencia del Congreso, oída la Junta de Portavoces, dictará las normas que garanticen la confidencialidad de la información que sobre materias clasificadas facilite el Gobierno"» ${ }^{12}$. La consecuencia fue la aprobación de la Resolución de la Presidencia de 18 de diciembre de 1986, sobre acceso por el Congreso de los Diputados a materias clasificadas ${ }^{13}$.

La citada resolución ya reconocía, como han hecho las posteriores de 1992 y 2004, que la petición de información al efecto no era una atribución individual de los diputados, sino que se articulaba a través de los grupos

12 Boletin Oficial de las Cortes Generales, Congreso de los Diputados, III Legislatura, Serie D, núm. 12, 23 de octubre de 1986, p. 182.

13 Boletin Oficial de las Cortes Generales, Congreso de los Diputados, III Legislatura, Serie E, núm. 14, 19 de diciembre de 1986, p. 467. 
parlamentarios, en concreto «uno o más grupos parlamentarios que comprendan, al menos, la cuarta parte de los miembros de la Cámara» (apartado segundo.1), y de las Comisiones de la Cámara, aunque en aquella se decía que ello «no afecta al derecho individual de los diputados a obtener información en los términos que establece el Reglamento de la Cámara» (apartado primero). Las resoluciones posteriores han obviado esta última referencia porque el derecho de que se trata es aplicación del señalado art. $109 \mathrm{CE}$, que se refiere a un derecho «colegiado» de la Cámara y no individual de cada diputado según los términos del art. 7.2 RCD, que no resulta de aplicación del art. $109 \mathrm{CE}$, sino del art. $23 \mathrm{CE}$.

La información se facilitaba de forma diversa según su contenido. Si estaba clasificada como secreto, el Gobierno la facilitaba «a tres diputados pertenecientes a grupos parlamentarios diferentes, elegidos al efecto por el Pleno de la Cámara, por mayoría de tres quintos, para la totalidad de la legislatura» (apartados segundo.2 y tercero.2 para el caso de las Comisiones). Si lo estaba como reservado, el Gobierno facilitaba «la información a los portavoces de los grupos parlamentarios y a las agrupaciones de diputados» (apartados segundo. 3 y tercero. 3 para el caso de las Comisiones). Motivadamente, y con carácter excepcional, el Gobierno podía solicitar de la Mesa de la Cámara que la información solicitada sobre determinada materia declarada secreta pudiera facilitarse exclusivamente al presidente de la Cámara (apartado segundo.4) o de la Comisión que la hubiese solicitado (apartado tercero.4). También podía el Gobierno «solicitar informar sobre una determinada materia clasificada a la Comisión competente por razón del asunto, en sesión secreta, con asistencia únicamente de los miembros de aquella» (apartado segundo.4 in fine), así como solicitar «que la información sobre una determinada materia declarada clasificada sea facilitada a la Comisión en sesión secreta. En este caso, solo podrán asistir a la sesión informativa los miembros de la Comisión» (apartado tercero.4 in fine).

Como en las resoluciones posteriores, cuando la información se refería al contenido de un documento, se exhibiría el original o fotocopia del mismo si los diputados entendían que sin el conocimiento directo de los documentos la información resultaba incompleta. En ese caso, los diputados podían tomar notas, pero no obtener copias ni reproducciones (apartado cuarto). En fin, se aplicaba el art. 16 RCD y los diputados que conocieran de esas materias debían guardar secreto sobre lo que habían conocido (apartado quinto).

Aquella Resolución de 1986 tuvo la virtualidad de ser la primera que regulaba este tema, extremo ya de por sí importante, pero lo hacía de mane- 
ra cicatera en algunos extremos y eso motivó las críticas de los propios diputados constatando la necesidad de modificarla parcialmente. Así, por ejemplo, se cuestionaba que fueran solo tres los diputados que conocieran la información de las materias clasificadas en la categoría de secreto, sin aclarar además los criterios y la forma concreta para elegirlos. De esta manera, en 1992 la ponencia constituida en la Comisión de Reglamento del Congreso de los Diputados para el estudio de la reforma del Reglamento de la Cámara elevó a la Mesa del Congreso una propuesta que incluía la modificación del entonces mecanismo para conocer la información sobre materias clasificadas. Como se obtuvo un acuerdo sobre la necesidad de introducir cambios en el sistema vigente hasta entonces, la Presidencia de la Cámara, de acuerdo con el art. 32.2 RCD y previo parecer favorable de la Mesa del Congreso de los Diputados y de la Junta de Portavoces, dictó la Resolución de la Presidencia del Congreso de los Diputados de 2 de junio de 1992, sobre acceso por el Congreso de los Diputados a secretos oficiales ${ }^{14}$.

La gran novedad de la nueva resolución se encontraba en su punto tercero ab initio, según el cual «si la materia en cuestión hubiera sido clasificada en la categoría de secreto, el Gobierno facilitará la información recabada a un diputado por cada grupo parlamentario de los constituidos, de conformidad con lo previsto en el art. 23.1 del Reglamento de la Cámara. Los diputados serán elegidos al efecto por el Pleno de la Cámara por mayoría de tres quintos». La remisión al art. 23.1 RCD significaba referirse solo a los grupos parlamentarios convencionales, pero no al Grupo Mixto contemplado en el art. 25 RCD y al que pertenecían aquellos diputados que no pudieron formar grupo propio por no alcanzar para ello el número mínimo previsto en el art. 23.1. La razón de la norma era clara. En aquellos momentos la formación Herri Batasuna tenía representación en el Congreso de los Diputados ${ }^{15}$ y no se creía oportuno que algún parlamentario miembro de esa formación tuviera acceso a material altamente sensible que afectara a la seguridad del Estado. Por eso, la cita textual del mencionado art. 23.1 RCD que no era de aplicación a la constitución del Grupo Mixto al que pertenecían tradicionalmente los diputados de Herri Batasuna.

La tercera y vigente resolución sobre el particular tiene precisamente su origen en la circunstancia que acaba de mencionarse. Ilegalizada Herri

${ }^{14}$ Boletin Oficial de las Cortes Generales, Congreso de los Diputados, IV Legislatura, Serie E, núm. 208, 3 de junio de 1992, p. 2.

15 Según la celebración de las distintas elecciones al Congreso de los Diputados, su representación en la Cámara fue la siguiente: 1979: 3; 1982: 2; 1986: 5; 1989: 4; 1993: 2, y 1996: 2 . 
Batasuna por Sentencia de 27 de marzo de 2003 del Tribunal Supremo, Sala Especial, del art. 61 de la Ley Orgánica del Poder Judicial, en aplicación de la Ley Orgánica 6/2002, de 27 de junio, de Partidos Políticos, se consideró que aquella prevención que se plasmó en la Resolución de 1992 había perdido su sentido y que había que recoger la figura de los grupos parlamentarios en general como titulares del derecho a solicitar y recibir información sobre las materias clasificadas en aplicación de la LSO. Por ello, al principio de la VIII Legislatura se consideró necesario modificar la regulación al efecto y de ese modo se aprobó la Resolución de la Presidencia del Congreso de los Diputados de 11 de mayo de 2004, sobre secretos oficiales ${ }^{16}$, cuyo contenido es coincidente con la Resolución de 1992, salvo que ahora ya no consta la mención del art. 23.1 RCD, con lo que, en la actualidad, todos los grupos parlamentarios existentes en la Cámara Baja pueden recibir la información sobre materias clasificadas según la LSO.

\section{LA REGULACIÓN ACTUAL SOBRE ACCESO DE LOS PARLAMENTARIOS A LAS MATERIAS CLASIFICADAS}

Como se ha indicado anteriormente, la normativa aplicable en la actualidad sobre acceso por los parlamentarios a las materias clasificadas con arreglo a la LSO viene contenida en la Resolución de la Presidencia del Congreso de los Diputados de 11 de mayo de 2004, sobre secretos oficiales. Las principales notas características de este sistema de acceso son las siguientes:

1. Conocimiento solo por el Congreso de los Diputados. La primera idea a destacar es que el acceso a las materias de referencia no afecta a todos los parlamentarios integrantes de las Cortes Generales, porque en el caso del Senado ni su reglamento ni norma posterior de la Presidencia de la Cámara regulan procedimiento alguno para que sus integrantes puedan conocer este tipo de documentación. Ello es una prueba más de la desigualdad competencial entre las dos Cámaras en detrimento del Senado, porque los grandes mecanismos de control parlamentario al Gobierno (moción de censura, cuestión de confianza, convalidación de los decretos-leyes o autorización de referéndum consultivo) se formalizan únicamente en el Congreso de los Diputados y no en el Senado, que tiene pocas competencias exclusi-

${ }^{16}$ Boletin Oficial de las Cortes Generales, Congreso de los Diputados, VIII Legislatura, Serie D, núm. 14, 12 de mayo de 2004, pp. 1-2. 
vas (por ejemplo, art. 155 CE) y siempre ligadas a su carácter de Cámara de representación territorial (art. 69.1 CE). La Constitución es poco generosa con el Senado y sus integrantes no han sabido o no han querido suplir con su iniciativa ese déficit, y una prueba de ello es la inexistencia de un procedimiento de acceso a las materias clasificadas. Es más, si en alguna ocasión se ha pretendido que el Senado adoptase alguna decisión sobre este tipo de materias, el resultado ha sido negativo. Viene esta reflexión al hilo de los acontecimientos desarrollados en relación con el caso de los llamados papeles del Cesid, en concreto en lo referente a la petición de tres magistrados para que el Gobierno les entregara determinada documentación referente a la guerra sucia contra el terrorismo que al estar clasificada con arreglo a la LSO no se les podía poner de manifiesto. Si bien en el Congreso habían podido ver los papeles que esos magistrados reclamaban, no fue en la Cámara Baja, sino en el Senado, donde se pretendió adoptar un acuerdo para instar al Gobierno a entregar a los magistrados la documentación que reclamaban para adjuntarla a los sumarios que estaban instruyendo, aunque el resultado de la votación celebrada el 26 de octubre de 1995 sobre la iniciativa del senador de Izquierda Unida Álvaro Martínez Sevilla no dejó dudas: 5 votos a favor (PNV y Grupo Mixto) y 208 en contra (PP, PSOE y $\mathrm{CiU})^{17}$. Estaba claro que el Senado no quería, y la situación sigue siendo la misma, involucrarse en el tema de las materias clasificadas.

2. Inexistencia en el Congreso de los Diputados de un órgano propio para el conocimiento de las materias clasificadas. Aunque en el lenguaje periodístico, en el popular y aun en el parlamentario el conocimiento de estas materias se produce en la Comisión de Secretos Oficiales del Congreso de los Diputados, esa alusión es inexacta porque realmente no existe dicha Comisión, sino que el acceso por los diputados a las materias clasificadas en aplicación de la LSO se produce en la Comisión de control de los créditos destinados a gastos reservados, con lo cual el objeto de dicha Comisión es más amplio, aunque hay que decir que las materias clasificadas lo pueden ser tanto por decisión del Consejo de Ministros (art. 4 LSO) como «sin necesidad de previa clasificación, las materias así declaradas por Ley» (art. 1.2 LSO), como es el caso de los gastos reservados, considerados secretos según el art. 3 de la Ley 11/1995, de 11 de mayo, reguladora de la utilización y control de los créditos destinados a gastos reservados.

${ }_{17}$ Cortes Generales, Diario de Sesiones del Senado, V Legislatura, núm. 94, Sesión del Pleno, jueves 26 de octubre de 1995, p. 4923. 
3. Conocimiento limitado a ciertos diputados. La Comisión de la que hablamos es una Comisión sui generis en cuanto a su composición, y en este sentido no se le aplica el art. 40.1 RCD según el cual las Comisiones «salvo precepto en contrario, estarán formadas por los miembros que designen los grupos parlamentarios en el número que, respecto de cada uno, indique la Mesa del Congreso, oída la Junta de Portavoces, y en proporción a la importancia numérica de aquellos en la Cámara». En el caso en presencia sí hay «precepto en contrario», la Resolución de la Presidencia de la Cámara de 11 de mayo de 2004.

El punto principal de diferencia entre el citado art. 40.1 RCD y la Resolución de 11 de mayo de 2004, a los efectos que se comentan, estriba en que en aquel los diputados son elegidos por cada grupo parlamentario, mientras que en la resolución se dice expresamente en el punto tercero que «los diputados serán elegidos al efecto por el Pleno de la Cámara por mayoría de tres quintos. Si alguno de los designados dejase de pertenecer, en el transcurso de la legislatura, al grupo parlamentario por el que fue elegido, se procederá a la elección de su sustituto por el procedimiento previsto en el párrafo anterior». Sí es de aplicación, y en la X Legislatura se ha utilizado en varias ocasiones, la posibilidad prevista en el art. 40.2 RCD de que los grupos parlamentarios puedan sustituir a uno de sus miembros adscritos a una determinada Comisión.

El hecho de que los miembros de la Comisión sean elegidos por el Pleno de la Cámara es importante, porque los grupos parlamentarios se limitan a realizar una propuesta que necesita la mayoría de tres quintos, es decir, 210 votos a día de hoy. Eso implica que si alguno de los grupos mayoritarios en la Cámara no está de acuerdo con una propuesta determinada, esta no podrá salir adelante. Eso sucedió, precisamente, en la X Legislatura, en la que la Comisión estuvo incompleta porque el Grupo Mixto careció de representante al oponerse el Partido Popular a los diputados propuestos por el citado grupo, cuyos miembros entendieron que «el atropello que sufrimos en el inicio de esta legislatura no tiene precedentes en la democracia española» ${ }^{18}$. En efecto, los integrantes de la Comisión en la X Legislatura se eligieron el 23 de febrero de 2012 y en esa ocasión el Partido Popular se opuso a que por el Grupo Mixto se eligiera a Alfred Bosch i Pascual, de Esquerra Republicana de Catalunya, como él mismo denunció en la cita-

18 Tardà i Coma, Cortes Generales, Diario de Sesiones del Congreso de los Diputados, Pleno y Diputación Permanente, X Legislatura, núm. 258, Sesión plenaria núm. 241, jueves 12 de febrero de 2015, p. 37. 
da sesión, porque los miembros del Partido Popular «a través de su portavoz parlamentario, dicen que estamos al servicio de Amaiur» ${ }^{19}$, los independentistas vascos presentes en el Congreso en esa legislatura. El portavoz del Partido Popular defendió la postura de su grupo argumentando que «aquí no hay vetos hacia su persona [...] ni cordones sanitarios [...] aquí hay simplemente la expresión máxima de la democracia, que se expresa no a través de la unanimidad, sino a través de la decisión democrática de cada uno de los diputados de esta Cámara» ${ }^{20}$. Sea cual sea la interpretación que se haga, lo cierto es que el Partido Popular se opuso a la presencia de Bosch en la Comisión y no hubo representante del Grupo Mixto en la primera elección.

En aplicación de los arts. 204 y 205 RCD, el diputado Jorquera Caselas, del Bloque Nacionalista Galego integrado en el Grupo Mixto, solicitó nueva votación para completar la composición de la Comisión ${ }^{21}$, votación que se realizó el 12 de abril de 2102 presentando ahora el Grupo Mixto como candidato a Joan Tardá i Coma, también de Esquerra Republicana de Catalunya. La sesión fue importante porque intervinieron representantes de algunos grupos parlamentarios como Lara Moya, de Izquierda Unida, que enlazó la votación con el art. 23 de la Constitución entendiendo que con el rechazo a la presencia del Grupo Mixto en la Comisión «se está cuestionando la propia Constitución española en sus partes fundamentales» ${ }^{22}$. En esta ocasión, el portavoz popular no vinculó la propuesta con Amaiur, sino que argumentó su negativa al señor Tardà en dos ideas: primera, «aquí no hay vetos ni nada que se le parezca, ni vetos ni crímenes, hay sencillamente votos, la libertad de votar, optar, elegir y valorar la idoneidad de unas personas que forman parte o que se han constituido en candidatos de un Grupo Mixto en virtud de una situación que usted sabe y conoce» ${ }^{23}$, y segunda, «lo único que se hace es evaluar si la persona que hoy propone el Grupo Mixto representa lo que es la pluralidad de ese grupo. Y sigo insistiéndole, señor Tardà, me da la sensación de que eso no lo representa» ${ }^{24}$. Tardà no salió elegido.

19 Bosch i Pascual, Cortes Generales, Diario de Sesiones del Congreso de los Diputados, Pleno y Diputación Permanente, X Legislatura, núm. 14, Sesión plenaria núm. 13, jueves 23 de febrero de 2012, p. 18.

${ }^{20}$ Hernando Fraile, ibid., p. 19.

${ }^{21}$ Jorquera Caselas, ibid.

22 Lara Moya, Cortes Generales, Diario de Sesiones del Congreso de los Diputados, Pleno y Diputación Permanente, X Legislatura, núm. 26, Sesión plenaria núm. 25, jueves 12 de abril de 2012, p. 68.

${ }^{23}$ Hernando Fraile, ibid., p. 69.

${ }^{24}$ Hernando Fraile, ibid., pp. 69-70. 
Tampoco el Grupo Mixto consiguió representación el 15 de noviembre de 2012 cuando propuso a la señora Jordà i Roura, también de Esquerra Republicana de Catalunya, quien en un apasionado discurso ${ }^{25}$ criticó la postura del Partido Popular en las anteriores votaciones aludiendo a que «Tejero volvió a este Parlamento» o que «hubo un nuevo alzamiento contra la democracia republicana», alusiones consideradas por el representante del Partido Popular en el sentido de que la diputada catalana «ha confundido esto con un mitin de campaña» ${ }^{26}$, y justificando el voto negativo de su grupo recriminándola que «no se puede pedir estar en una Comisión de Secretos Oficiales que tiene que garantizar — ¿verdad? — la seguridad del Estado, el cumplimiento de nuestras leyes, nuestras normas, nuestra Constitución, nuestros acuerdos internacionales y nuestros intereses en defensa y, a la vez, estar proclamando cada día -incluso también en esta Cámara- que lo que ustedes buscan es destruir esa seguridad, eso que nos une y que nos ha hecho ser grandes durante tanto tiempo, señoría ${ }^{27}$. La señora Jordà no obtuvo los 210 votos precisos y el Grupo Mixto siguió sin representación en la Comisión.

El Grupo Mixto tampoco obtuvo puesto en la Comisión en la votación de 14 de marzo de 2013 cuando hubo que sustituir a Josu Erkoreka, del Grupo Vasco, que había renunciado a su acta de diputado para integrarse en el Gobierno vasco. De nuevo la posición del Partido Popular impidió a Alfred Bosch ser miembro de la Comisión en la que entró por el PNV Aitor Esteban ${ }^{28}$. Lo mismo sucedió cuando el 16 de octubre de 2014 se votó la sustitución en la Comisión de Soraya Rodríguez Ramos, del Grupo Parlamentario Socialista, por Antonio Hernando Vera ${ }^{29}$.

La última votación sobre el modo de integrar la Comisión tuvo lugar el 12 de febrero de 2015 con el objeto de sustituir al representante del Grupo Parlamentario Popular por la vacante de su representante, Alfonso Alonso, que había sido nombrado ministro de Sanidad. De nuevo Tardà i Coma

25 Jordà i Roura, Cortes Generales, Diario de Sesiones del Congreso de los Diputados, Pleno y Diputación Permanente, X Legislatura, núm. 74, Sesión plenaria núm. 70, jueves 15 de noviembre de 2012, p. 60.

${ }^{26}$ Hernando Fraile, ibid., p. 62.

27 Ibid.

${ }^{28}$ Cortes Generales, Diario de Sesiones del Congreso de los Diputados, Pleno y Diputación Permanente, X Legislatura, núm. 97, Sesión plenaria núm. 91, jueves 14 de marzo de 2013, p. 91.

${ }^{29}$ Cortes Generales, Diario de Sesiones del Congreso de los Diputados, Pleno y Diputación Permanente, X Legislatura, núm. 231, Sesión plenaria núm. 216, jueves 16 de octubre de 2014. p. 4. 
denunció lo que a su juicio era un atropello al negar el Partido Popular su apoyo a un candidato del Grupo Mixto procedente de Esquerra Republicana de Catalunya, en su opinión porque «éramos independentistas y amigos de los independentistas vascos presentes en este Parlamento, elegidos democráticamente por la ciudadanía vasca, de los compañeros y compañeras de Amaiur. No fuera que pasáramos información» ${ }^{30}$. La respuesta de Bermúdez de Castro por el Partido Popular se centró en el carácter especial de la Comisión de que se trataba «por lo que a los diputados que quieran formar parte de la misma se les debe exigir un compromiso de discreción, pero también un plus de lealtad con el Estado [...] que no se puede presumir de todos los diputados» ${ }^{31}$. Resultó elegido miembro de la Comisión Rafael Hernando Fraile, del Partido Popular, y el señor Tardà solo obtuvo un voto. El Grupo Mixto no estuvo presente, pues, en la Comisión durante la X Legislatura.

Con independencia de los nombres concretos que integren la Comisión, lo importante es el carácter con el que lo hacen y eso lo resumió perfectamente el senador Barbuzano González al hablar de «una serie de señores en los que reside la soberanía delegada de todos los españoles [...] una serie de señores a los que el pueblo les ha dicho: voy a delegar en ustedes, por una serie de años, mi soberanía» ${ }^{32}$. Por esa razón, cualquier negativa a que un miembro de un grupo parlamentario forme parte de la Comisión puede interpretarse contraria al espíritu constitucional de entender las Cortes Generales como representantes del pueblo español (art. 66.1 CE), por ello se ha dicho en la propia Comisión que «vetar un nombre para una comisión es igual que vetar a los ciudadanos que han dado el apoyo a los grupos que conforman el Grupo Mixto y tienen derecho a tener sus representantes en todas las comisiones de esta Cámara» ${ }^{33}$ y que «cuando el Partido Popular hasta ahora ha vetado al Grupo Mixto no solo restringe los derechos políticos de ese grupo, sino que le está negando los derechos democráticos a todos los ciudadanos que lo han votado» ${ }^{34}$.

30 Tardà i Coma, Cortes Generales, Diario de Sesiones del Congreso de los Diputados, Pleno y Diputación Permanente, X Legislatura, núm. 258, Sesión plenaria núm. 241, jueves 12 de febrero de 2015, p. 38.

31 Bermúdez de Castro Fernández, ibid., p. 39.

32 Barbuzano González, Cortes Generales, Diario de Sesiones del Senado, V Legislatura, núm. 94, Sesión del Pleno del jueves, 26 de octubre de 1995, p. 4922.

33 Lara Moya, Cortes Generales, Diario de Sesiones del Congreso de los Diputados, Pleno y Diputación Permanente, X Legislatura, núm. 14, Sesión plenaria núm. 13, jueves 23 de febrero de 2012, p. 68.

${ }_{34}$ Coscubiela Conesa, Cortes Generales, Diario de Sesiones del Congreso de los Diputados, Pleno y Diputación Permanente, X Legislatura, núm. 97, Sesión plenaria núm. 91, jueves 14 de marzo de 2013, p. 89. 
4. Procedimiento plural de facilitar la información. En la Resolución de 11 de mayo de 2004 se establecen varias modalidades de proporcionar la información según la clasificación de las materias de que se trate. Así, según el punto tercero, «si la materia hubiera sido clasificada de secreto, el Gobierno facilitará la información recabada a un diputado por cada grupo parlamentario». Por otra parte, «si la materia en cuestión hubiera sido clasificada en la categoría de reservado, el Gobierno facilitará la información a los portavoces de los grupos parlamentarios o a los representantes de los mismos en la Comisión, cuando hubiera partido de esta la iniciativa de la solicitud» (apartado cuarto). Realmente la diferencia se produce pocas veces, porque la costumbre es que los distintos grupos parlamentarios propongan como representante en la Comisión a su portavoz en la Cámara, con lo cual en la mayoría de las ocasiones los diputados a los que se refieren los dos puntos citados de la resolución son los mismos.

La resolución contempla la posibilidad de iniciativa del Gobierno respecto al procedimiento para facilitar determinadas informaciones. En ese sentido, en primer lugar, el punto quinto establece que «motivadamente, y con carácter excepcional, el Gobierno podrá solicitar de la Mesa de la Cámara que la información sobre una determinada materia declarada secreta sea facilitada exclusivamente al presidente del Congreso o al de la Comisión, cuando la petición hubiese sido formulada por esta última. Corresponde, en todo caso, a la Mesa del Congreso la resolución definitiva sobre la solicitud del Gobierno». Se reconoce, pues, en principio al Gobierno una potestad discrecional que puede condicionar el ejercicio de las atribuciones de la Comisión, por lo que «el controlado» asume así un significado inicial poco acorde con su condición de alguien a quien se demanda información, situación solo superada por la decisión final de la Mesa de la Cámara. Es importante señalar, en segundo lugar, el punto sexto de la resolución según el cual «asimismo, el Gobierno podrá solicitar que la información sobre una determinada materia clasificada sea facilitada en sesión secreta a la Comisión que la demandó o a cualquier Comisión competente en la materia, en el caso de que la iniciativa hubiese partido de los grupos parlamentarios. En estos supuestos, solo podrán asistir a la sesión informativa los miembros de la Comisión».

La cuestión es de gran importancia porque se refiere al procedimiento para poner de manifiesto información clasificada que haya sido solicitada por cualquier Comisión de la Cámara, de forma especial cuando se trata de comisiones de investigación como sucedió con la comisión de investigación del 11 de marzo. En efecto, dicha comisión solicitó del Gobierno el 
envío de determinada documentación clasificada según la LSO. El ejecutivo estaba dispuesto a enviar al Congreso ciertos documentos a la Comisión de control de los créditos destinados a gastos reservados, pero en aquel momento (2004) el único miembro de dicha Comisión que lo era también de la comisión de investigación era el presidente de esta última, Paulino Rivero, de Coalición Canaria, con lo que el trámite resultaba en principio inútil porque solo él podría analizar la documentación. Para desbloquear la situación, el Gobierno accedió a que la documentación fuera analizada por la propia comisión de investigación en sesión secreta y como mejor dispusiera el Congreso. En este sentido, con presencia de personal del Centro Nacional de Inteligencia encargado de la custodia de la información, la comisión de investigación celebró dos sesiones secretas, el 13 de julio de 2004 y el 14 de octubre del mismo año. En la primera pudo analizar una veintena de documentos del Centro Nacional de Inteligencia sobre evaluación de amenazas de Bin Laden el 27 de octubre de 2003, atentados en Casablanca el 16 de mayo de 2003, informes sobre Irak, etc. En cambio, el Gobierno no aportó seis informes solicitados por Esquerra Republicana de Catalunya e Izquierda Unida que habían sido realizados por los servicios de inteligencia de Marruecos sobre los atentados de Casablanca y por la CIA, el Mossad y el MI6 en relación con los atentados de Madrid y sus autores. La explicación es que el art. 11.2 de la Ley 11/2002, de 6 de mayo, reguladora del Centro Nacional de Inteligencia, excluye del acceso por la Comisión de control de los créditos destinados a gastos reservados, de las materias «que procedan de servicios extranjeros u organizaciones internacionales en los términos establecidos en los correspondientes acuerdos y convenios de intercambio de información clasificada». La segunda sesión secreta de la comisión de investigación se celebró el 14 de octubre de 2004 y en ella pudieron analizar informes de la Guardia Civil sobre la trama de los explosivos utilizados en los atentados o informes de Europol sobre amenazas del terrorismo islámico radical.

5. Eficacia limitada en cuanto a resultados obtenidos de la información facilitada. Con ello se quiere decir que es difícil hacerse una idea completa sobre un tema que haya sido analizado en la Comisión porque realmente no se puede tener certeza absoluta de que la documentación examinada sea toda la existente sobre la materia ni que el compareciente ante la Comisión haya facilitado la información que obra en su poder y de la que haya tenido conocimiento por razón de su cargo. Se trata, en realidad, muchas veces de un ejercicio de confianza política más que de la seguridad de que lo que los diputados miembros de la Comisión han visto 
y oído en ella sea la información completa sobre todos los aspectos que ellos quisieran plantear. Las sesiones, pues, de la Comisión defraudan a veces las expectativas de sus integrantes o simplemente estos no saben qué datos claves sobre una materia no se les ponen de manifiesto. Durante la primera Guerra del Golfo, la Comisión recibió información del Gobierno, pero nadie informó de que algunos de los B-52 americanos que atacaban Irak despegaban de la Base de Morón, dato que se conoció por una intervención en el Parlamento británico del Premier John Major. Más recientemente, el secretario de Estado-director del Centro Nacional de Inteligencia compareció ante la Comisión el 19 de marzo de 2013 para hablar de la princesa Corinna zu Sayn-Wittgenstein y su presunta relación con los servicios de inteligencia españoles. No sabemos el contenido de su declaración, pero si hacemos buenas las palabras publicadas en su momento, «ninguno de los parlamentarios consiguió que dijera nada, ni siquiera Josep Antoni Durán i Lleida, portavoz de CiU, que llegó a espetarle: “general, ¿tiene algo que contarnos sobre Corinna?” ${ }^{35}$. Apelando al refranero español, «para ese viaje no hacen falta alforjas».

6. Aparente, al menos, contradicción normativa. La regulación de los secretos oficiales no está contenida en una única norma. Bien al contrario, hay una pluralidad de disposiciones que no siempre conforman un todo unitario y coherente. Como sabemos, la norma base es la LSO de abril de 1968, reformada el 11 de octubre de 1978. En el art. 10.Dos de la LSO se dice que «la declaración de "materias clasificadas" no afectará al Congreso de los Diputados ni al Senado, que tendrán siempre acceso a cuanta información reclamen, en la forma que determinen los respectivos reglamentos $\mathrm{y}$, en su caso, en sesiones secretas». Al margen del procedimiento concreto para hacer posible esa información y del hecho de que en el Senado no hay previsión alguna sobre el particular, lo cierto es que ese precepto tiene alguna contradicción con el art. 11, parcialmente citado con anterioridad, de la Ley 11/2002, de 6 de mayo, reguladora del Centro Nacional de Inteligencia. En efecto, en su párrafo 1 se dice que «el Centro Nacional de Inteligencia someterá al conocimiento del Congreso de los Diputados, en la forma prevista en su Reglamento, a través de la Comisión que controla los créditos destinados a gastos reservados, presidida por el presidente de la Cámara, la información apropiada sobre su funcionamiento y actividades. El contenido de dichas sesiones y sus deliberaciones será

35 A. Romero, Final de partida. La crónica de los hechos que llevaron a la abdicación de Juan Carlos I, Madrid, La Esfera de los Libros, 2015, p. 230. 
secreto». En realidad, el tenor literal del epígrafe de ese art. 11 («Control parlamentario») resulta defraudado con el contenido de ese primer párrafo porque solo alude al control por el Congreso, con manifiesto olvido del Senado, y porque la referencia información apropiada de suyo alude a un grado de discrecionalidad del Centro y del Gobierno para determinar lo que van a informar y sobre lo que el Congreso tendrá poca capacidad de modificación. El punto 2 del artículo de referencia ha sido ya citado con anterioridad y los restantes párrafos del artículo no son relevantes en relación con el extremo que se analiza.

Tenemos, pues, una norma que establece un principio general, la LSO, y una norma específica, la Ley 11/2002, de 6 de mayo, que matiza esa previsión general. No sabemos si tenía razón Mardones Sevilla cuando en la tramitación parlamentaria de la última de esas leyes decía que «lo que faltaba es que el Centro Nacional de Inteligencia se hiciera el traje a medida de cómo tiene que quedar la comisión de control parlamentario correspondiente, la de secretos oficiales, la de fondos reservados, la que sea, la que se instituya, pero ha de instituirla el Congreso de los Diputados, a la vista de esto que ha salido» ${ }^{36}$, o si la razón la tenía Atencia Robledo, del Partido Popular, al responderle que «el control parlamentario diseñado en el proyecto de ley respeta escrupulosamente la autonomía parlamentaria y, por tanto, las decisiones de la Mesa y las resoluciones de la Presidencia del Congreso, especialmente la resolución de la Presidencia del Congreso de 2 de junio de 1992 sobre secretos oficiales» ${ }^{37}$. Lo cierto es que parece razonable que el control parlamentario de nuestro servicio de inteligencia deba moverse dentro de los parámetros de la seguridad jurídica y de la transparencia, pero también de la lógica que impone restricciones a ese control derivado del mínimo sentido común, dado el contenido altamente sensible de las materias de las que hablamos. Realmente, parece más oportuno hablar de una cierta inocencia de la LSO y su reforma de 1978 al pretender establecer un control parlamentario universal sobre los secretos oficiales, ingenuidad sin duda derivada del hecho de que esa reforma, aun anterior a la aprobación de la Constitución, se llevó a cabo a la vista del texto ya elaborado y de su potencial carácter taumatúrgico. La lógica a veces impone su fuerza y atempera los deseos.

${ }^{36}$ Mardones Sevilla, Cortes Generales, Diario de Sesiones del Congreso de los Diputados, Comisiones, VII Legislatura, núm. 423, Defensa, Sesión núm. 21, miércoles 20 de febrero de 2002, p. 13682.

37 Atencia Robledo, ibid., p. 13701. 
7. Constancia posterior limitada del contenido de la documentación recibida en la Comisión. El punto octavo de la Resolución de 11 de mayo de 2004 señala que sus diputados «podrán examinar por sí mismos la documentación, en presencia de la autoridad que la facilite, y podrán tomar notas, pero no obtener copias ni reproducciones». La fiabilidad del resultado de esas comparecencias puede quedar matizada por la versión o el «resumen» que los diputados hagan de la información recibida que, además y legítimamente, cada uno puede interpretar desde su óptica política y personal.

8. Reserva sobre las informaciones recibidas en la Comisión. Es este un extremo de singular importancia en el tema de que se trata. El punto noveno de la Resolución de 11 de mayo de 2004 establece que «lo dispuesto en el art. 16 del Reglamento de la Cámara será de aplicación a las actuaciones de los diputados relacionadas con la materia que regula la presente resolución ${ }^{38}$. El citado artículo señala que «los diputados están obligados a adecuar su conducta al reglamento y a respetar el orden, la cortesía y la disciplina parlamentaria, así como a no divulgar las actuaciones que, según lo dispuesto en aquel, puedan tener excepcionalmente el carácter de secretas». Obviamente, interesa sobre todo la última referencia sobre el mantenimiento del secreto propio de las sesiones de la Comisión. Con ese deber de los diputados se logra que la reserva propia del trabajo de la Comisión se prolongue en el tiempo, pero como consecuencias anexas significa de suyo que el conocimiento que sobre determinadas cuestiones hayan obtenido sus integrantes no puede, o no debe, ser utilizado públicamente en el debate político, pero, lo que tal vez sea más significativo, tampoco puede ser utilizado en procedimientos judiciales. Por eso es importante recordar que el 20 de agosto de 1996, el presidente de la Sala Segunda del Tribunal Supremo, en funciones de presidente del Tribunal Supremo, envió al presidente del Congreso de los Diputados la petición del magistrado de la Audiencia Nacional Javier Gómez de Liaño para que comparecieran y testificaran los seis integrantes de la Comisión de control de los créditos destinados a gastos reservados de la legislatura anterior y que en sesión de la Comisión de 2 de octubre de 1995 habían tenido conocimiento de determinada documentación del CESID sobre el caso Lasa y Zabala, que el citado magistrado estaba instruyendo, dentro del análisis de las 1.245 microfichas que había sustraído del CESID el coronel Perote, exjefe de la Agrupación Operativa del Centro.

38 Vid. J. A. Alonso DE AnTONIO, «El deber de secreto de los parlamentarios», Revista de la Facultad de Derecho. Universidad Complutense de Madrid, núm. 76 (1990), pp. 4-26. 
El testimonio de los diputados nunca se produjo porque desde el Congreso se adujo el carácter secreto de las sesiones de la Comisión y el deber de sus integrantes de mantener el mismo.

\section{CONCLUSIONES}

De las páginas que preceden se pueden extraer determinadas conclusiones. En primer lugar, el control parlamentario de los secretos oficiales en España es un control parcial, limitado al Congreso de los Diputados, en coherencia con la tradicional minusvaloración del Senado en la etapa democrática, pero escasamente respetuoso con el carácter bicameral de nuestro Parlamento y la igualdad funcional de ambas Cámaras según la Constitución. En segundo lugar, ese control no tiene un órgano específico, sino que se difumina dentro del órgano de control de los créditos destinados a gastos reservados. En tercer lugar, el conocimiento de estas cuestiones está limitado a un número escaso de diputados, pero se pretende, aunque no siempre se logra, que todas las fuerzas políticas presentes en la Cámara tengan una representación en la misma. Las diferentes posibilidades de transmitir la información a la Cámara plantean a veces problemas operativos para hacer posible esa comunicación y no siempre se han adoptado las medidas necesarias para asegurar la discreción que debe rodear estas cuestiones. Hay que destacar, por último, que el conocimiento de la documentación por los integrantes de la Comisión no supone obtener la misma para su depósito posterior, y en todo caso deben observar escrupuloso secreto sobre lo que han visto y oído en las sesiones a las que hayan asistido, en lógica con el carácter sensible de las materias e informaciones a las que han tenido acceso. 